TITLE:

\title{
Bioconversion of essential oil components of Perilla frutescens by Saccharomyces cerevisiae
}

$\operatorname{AUTHOR}(\mathrm{S})$ :

Kimura, Michiru; Ito, Michiho

\section{CITATION:}

Kimura, Michiru ...[et al]. Bioconversion of essential oil components of Perilla frutescens by Saccharomyces cerevisiae. Journal of Natural Medicines 2020, 74(1): 189-199

ISSUE DATE:

2020-01

URL:

http://hdl.handle.net/2433/245439

\section{RIGHT:}

This is a post-peer-review, pre-copyedit version of an article published in 'journal of Natural Medicines'. The final authenticated version is available online at: https://doi.org/10.1007/s11418-019-01363-y.; The full-text file will be made open to the public on 01 October 2020 in accordance with publisher's 'Terms and Conditions for Self-Archiving'; この論 文は出版社版でありません。引用の際には出版社版をご確認ご利用ください。; This is not the published version.

Please cite only the published version. 


\section{Bioconversion of essential oil components of Perilla frutescens by}

\section{Saccharomyces cerevisiae}

Michiru Kimura and Michiho Ito

Department of Pharmacognosy, Graduate School of Pharmaceutical Science, Kyoto

University, 46-29 Yoshida-Shimo-Adachi-cho, Sakyo-ku, Kyoto 606- 8501, Japan

Tel.: 075-753-4506; michihoi@pharm.kyoto-u.ac.jp (M. Ito) 


\title{
Bioconversion of essential oil components of Perilla frutescens by Saccharomyces cerevisiae
}

\author{
The essential oil of perilla (Perilla frutescens) contains volatile low molecular \\ weight compounds such as monoterpenes and phenylpropenes. The composition \\ of the essential oil is classified into about ten chemotypes. The biosynthesis of \\ these constituents is strictly controlled genetically. Among the compounds \\ contained in perilla essential oil, the bioconversion of pure compounds such as \\ perillaldehyde, limonene, and citral has been reported, but that of many other \\ components has not. In addition, changes in the volatile components of raw plant \\ material during brewing have also been investigated for wine and beer. In this \\ study, we examined the bioconversion of perilla essential oil components by \\ Saccharomyces cerevisiae during the brewing of liquor with perilla leaves. $S$. \\ cerevisiae was added to the ethanol-water extract of dried leaves of $P$. frutescens \\ and $P$. citriodora for seven essential oil types: perillaldehyde type, piperitenone \\ type, perillene type, perillaketone type, elsholtziaketone type, citral type, and \\ phenylpropanoid type. Volatile compounds in the reaction mixtures were \\ analyzed by solid-phase microextraction (SPME)-GC-MS, revealing \\ bioconversion of perillaldehyde, isoegomaketone, neral, and geranial by $S$. \\ cerevisiae. Analysis of the conversion products suggests that they were formed \\ by the reduction of $\mathrm{C}=\mathrm{C}$ bonds and aldehydes, as well as by esterification and \\ dehydration reactions.
}

Keywords: Perilla frutescens; bioconversion; Saccharomyces cerevisiae; monoterpenoids; trans-shisool; perillyl alcohol

\section{Introduction}

Perilla frutescens is an annual plant belonging to the family Labiatae and is used both as an herb in cooking and as a source of the natural medicine soyo. The composition of the essential oil obtained from perilla is classified into about a dozen types that are strictly controlled genetically (1). These essential oil types are divided into monoterpene types (Fig. 1) and phenylpropene types (Fig. 2) according to their structures. Perilla used for medicinal purposes in Japan is a perillaldehyde (PA) type and contains perillaldehyde as the main compound. Perillaldehyde has been reported to have antibacterial (2), vasodilator (3), and antidepressant (4) activities.

Many monoterpene compounds contained in plant essential oils have pharmacological actions such as antibacterial $(2,5)$, sedative $(6,7)$, and antitumor (8) activities and thus are useful in the pharmaceutical field. Monoterpenes are also used as 
flavors and fragrances because they typically have pleasant aroma and volatilize at room temperature. Furthermore, compounds such as camphor and $\alpha$-terpineol are synthesized by chemical conversion (9) or biotransformation by microorganisms (10, 11) from monoterpene compounds such as $\alpha$-pinene that are abundant in nature and inexpensively available as a raw material. Bioconversion by microorganisms rather than chemical conversion for the synthesis of compounds is advantageous because the reaction can be performed under mild conditions, multiple reactions can be performed in one step, and bioconversion often provides high stereo- and regiospecificity.

The bioconversion of monoterpene compounds by microorganisms such as molds $(10,12)$, basidiomycetes $(13)$, algae $(14)$, and yeasts $(15,16,17)$ has been investigated. Efforts are ongoing to identify microbial species that can convert monoterpene compounds efficiently and that are resistant to the toxicity of monoterpene compounds, and suitable reaction conditions are also being investigated $(15,18)$.

Microorganisms such as Saccharomyces cerevisiae have been used in brewing since antiquity. In brewing, yeast are mixed with plant materials such as grapes and malted barley (the raw materials for wine and beer, respectively) that contain various components, and then the mixture is incubated. Yeast both performs alcoholic fermentation to produce ethanol and carbon dioxide from sugar and converts volatile components of the raw plant material, such as geraniol into various other compounds $(16,19)$. Therefore, the bioconversion of volatile raw plant material components by yeast is an important factor determining the aroma of the finished alcoholic beverage. Brewing takes advantage of the action of microorganisms but the product is spoiled when miscellaneous bacteria contaminate the incubating mixture and proliferate. It is therefore necessary to prevent contamination by unwanted microorganisms. For example, in the brewing of beer, hops are added to the incubating mixture to suppress the growth of miscellaneous bacteria, and the alcohol produced by fermentation is also effective at preventing spoilage.

Research on the perilla perillaldehyde biosynthetic enzyme expressed by $S$. cerevisiae AH22 showed that perillyl alcohol and trans-shisool are generated when perillaldehyde is used as a substrate and control extracts prepared from $S$. cerevisiae AH22 lacking the target gene in the vector plasmid are used (20). Perillaldehyde (14, $17,21)$, limonene $(15,18)$, and citral $(14)$ are monoterpene compounds contained in perilla essential oil and their bioconversion have previously been reported. In this study we examined changes in aroma during brewing of perilla, as occurs with grapes, malted barley, and hops - that is, we examined changes in low molecular weight volatile compounds when $S$. cerevisiae was added to plant extracts. 


\section{Materials and Methods}

\section{1. Chemicals and solvents}

All chemical reagents and solvents were purchased from Nacalai Tesque Inc., Kyoto, Japan. Perillaketone and isoegomaketone standards were obtained as follows; the essential oil obtained by steam distillation of perillaketone (PK) type perilla (No. 6) was measured by headspace solid-phase microextraction (SPME)-GC-MS and the component composition was identical with that reported in the literature (22). Then, the essential oil was purified by column chromatography and compounds were identified from their retention time and mass spectral pattern.

\section{2. Plant materials}

Perilla plants were grown at the Experimental Station for Medicinal Plant Research, Graduate School of Pharmaceutical Science, Kyoto University. Oil types and strain numbers used in this study were as follows: perillaldehyde (PA) type, No. 32 and No. 5343; piperitenone (PT) type, No. 5598; perillene (PL) type, No. 1864; PK type, No. 63; elsholtziaketone (EK) type, No. 79; phenylpropanoid (PP) type, No. 1 of $P$. frutescens; and citral (C) type, No. 5809 of P. citriodora. All plants were bred and kept as pure lines by repeated self-pollination. The harvested perilla leaves were dried at room temperature and stored in a closed container with silica gel at $4^{\circ} \mathrm{C}$ until use.

\section{3. Yeast strain}

S. cerevisiae NBRC 2260 was purchased from the National Institute of Technology and Evaluation (NITE), Tokyo, Japan.

\section{4. Conversion of essential oil components of Perilla}

S. cerevisiae NBRC 2260 was inoculated into $100 \mathrm{~mL}$ of YPD medium (500 mL Erlenmeyer flask) and cultured at $30^{\circ} \mathrm{C}$ and $150 \mathrm{rpm}$ for $48 \mathrm{~h}$. This preculture was centrifuged at $4^{\circ} \mathrm{C}$ and $6000 \mathrm{rpm}$ for $5 \mathrm{~min}$ to remove the supernatant, after which $5 \%$ ethanol aqueous solution was added to the pellet and the turbidity (optical density 600 $\mathrm{nm}$ ) was measured. The cells were resuspended in $10 \%$ ethanol aqueous solution to a cell density of $5 \times 10^{8}$ cells $/ \mathrm{mL}$. The relational expression between the number of cells and the turbidity (number of cells $=$ turbidity $\times 1.44 \times 10^{7}$ cells $/ \mathrm{mL}$, valid for turbidity values of 0.5 or less) was obtained in advance under the same conditions. In an autoclaved $100 \mathrm{~mL}$ Erlenmeyer flask covered with aluminum foil, $49 \mathrm{~mL}$ of $10 \%$ 
ethanol aqueous solution and $0.025 \mathrm{~g}$ of dried perilla leaf ground with a grinder were added and shaken at $30^{\circ} \mathrm{C}$ and $150 \mathrm{rpm}$ for $1 \mathrm{~h}$, after which $1 \mathrm{~mL}$ of bacterial suspension was added $\left(1 \times 10^{7}\right.$ cells $\left./ \mathrm{mL}\right)$ and the mixture was shaken at $30^{\circ} \mathrm{C}$ and 100 rpm. After 0,24 , and $48 \mathrm{~h}$, shaking was terminated and the reaction solution was analyzed. The experiment was carried out in duplicate. We identified the components derived from yeast and the chemical conversion of perilla essential oil components by similarly analyzing reaction mixtures comprising yeast in $10 \%$ ethanol aqueous solution (yeast: $1 \times 10^{7}$ cells/mL) and reaction mixtures comprising perilla leaf immersion liquid not containing yeast (dried perilla leaf: $0.5 \mathrm{w} / \mathrm{v} \%$ ).

\section{5. Measurement of viable cell count}

After incubation for 24 and $48 \mathrm{~h}$, a reaction mixture comprising yeast in $10 \%$ ethanol aqueous solution and reaction mixtures comprising yeast in perilla leaf immersion liquids of each essential oil type were stained with methylene blue. The number of viable cells was calculated by counting the total number of cells and the number of stained cells under a microscope.

\section{6. SPME-GC-MS analysis of volatile compounds in the reaction mixture}

After incubation for 0,24 , and $48 \mathrm{~h}$, the reaction mixture comprising yeast and perilla leaf immersion liquid of each essential oil type, the reaction mixture comprising only perilla leaf immersion liquid of each essential oil type, and the reaction mixture comprising yeast in 10\% ethanol aqueous solution, were each filtered through No. 2 filter paper (Toyo Roshi Kaisha, Ltd., Tokyo, Japan) on ice and $1 \mathrm{~mL}$ of filtrate was placed in an SPME vial (Supelco Inc., Bellefone, PA) and stored at $-30^{\circ} \mathrm{C}$. Each sample was heated in an aluminum block thermostat (DTU-1B; Taitec Co., Ltd., Aichi, Japan) at $60^{\circ} \mathrm{C}$ for $20 \mathrm{~min}$, after which a SPME fiber (100 $\mu \mathrm{m}$ polydimethylsilane; Supelco) was inserted into the headspace of the vial for 5 min to absorb the volatile compounds. Desorption was carried out at $160^{\circ} \mathrm{C}$ for $10 \mathrm{~min}$ in the splitless injection unit of a GCMS instrument (6850 GC/5975 MSD; Agilent Technologies Japan, Ltd., Tokyo, Japan) equipped with a DB-WAX column $(60 \mathrm{~m} \times 0.25 \mathrm{~mm}, 0.25 \mu \mathrm{m}$ film thickness; Agilent Technologies). The oven temperature program began at $60^{\circ} \mathrm{C}$, increased by $5^{\circ} \mathrm{C} / \mathrm{min}$ to $140^{\circ} \mathrm{C}$, increased by $0.2^{\circ} \mathrm{C} / \mathrm{min}$ to $145^{\circ} \mathrm{C}$, increased by $10^{\circ} \mathrm{C} / \mathrm{min}$ to $235^{\circ} \mathrm{C}$, and was maintained for $5 \mathrm{~min}$. The detector temperature was $240^{\circ} \mathrm{C}$. He $(1.0 \mathrm{~mL} / \mathrm{min})$ was used as the carrier gas. The ionization voltage for the mass spectra was $70 \mathrm{eV}$. The mass range was from m/z 50 to 400 . The compounds were identified by comparing their mass spectral patterns with those in an MS database (NIST11; National Institute of Standards and Technology). Perillaketone and isoegomaketone were identified by comparing their mass spectral patterns (Figs. S1, S2) and retention times with those of authentic 
standards. 1,2-Dihydroperillaldehyde was identified by comparing its mass spectral pattern with a mass spectral pattern in the literature (21).

\section{7. GC-MS analysis of the hexane extract fraction of the reaction mixture}

After incubation for 0,24 , and $48 \mathrm{~h}$, the reaction mixture comprising yeast and perilla leaf immersion liquid of each essential oil type, the reaction solution comprising only perilla leaf immersion liquid of each essential oil type, and the reaction mixture comprising yeast were in $10 \%$ ethanol aqueous solution, were each filtered through No. 2 filter paper (Toyo Roshi Kaisha, Ltd.) on ice. (-)-Menthone $\left(2.88 \times 10^{-6} \mathrm{~mol} / \mathrm{L}\right)$ was added to $5 \mathrm{~mL}$ of each filtrate as an internal standard and the filtrate was extracted twice with about $5 \mathrm{~mL}$ of hexane. The hexane fraction was dehydrated with anhydrous sodium sulfate, concentrated, and $1 \mu \mathrm{L}$ was injected into the GC-MS. The split ratio was 99:1. The GC-MS instrument conditions, column, injection temperature, detector temperature, oven temperature program, carrier gas, ionization voltage, and mass range were the same as for SPME-GC-MS analysis.

\section{Results}

\section{1. Viable cell count}

Ethanol aqueous solution (10\%) was used to examine changes in low molecular volatile compounds during the brewing process and to inhibit the growth of unwanted microorganisms, since the perilla leaves were grown non-aseptically. We previously confirmed that the added yeast survived in the reaction solution.

We measured the number of viable bacteria in the reaction mixture comprising perilla leaf immersion liquid (10\% ethanol aqueous solution, $0.5 \mathrm{w} / \mathrm{v} \%$ of dried perilla leaf) and yeast and found that between $1.5 \times 10^{6}$ cells $/ \mathrm{mL}$ to $3.0 \times 10^{6}$ cells $/ \mathrm{mL}$ of yeast added to perilla leaf immersion liquids of all essential oil types survived after 24 and 48 h. Furthermore, about $8 \times 10^{5}$ cells/mL of yeast added to $10 \%$ ethanol aqueous solution without perilla leaf immersion liquid survived after 24 and 48 h (Table S1).

\section{2. SPME-GC-MS analysis of volatile compounds in the reaction mixture}

Ethyl decanoate was detected as a volatile component derived from yeast (Fig. 3a). We compared the components of the reaction mixture comprising yeast and perilla leaf immersion liquid of each essential oil type and the reaction mixture comprising only perilla leaf immersion liquid after incubation for 0,24 , and $48 \mathrm{~h}$. Changes in essential oil components were observed only when yeast were added to PA, PK, and C type 
perilla leaf immersion liquids (Fig. 3b-d). For the PA type sample, perillaldehyde decreased and perillyl alcohol, 1,2-dihydroperillaldehyde, trans-sisool, isolimonene, and perillyl acetate appeared (Fig. 3b). For the PK type sample, isoegomaketone decreased and perillaketone was formed (Fig. 3c), and in the $C$ type sample, neral and geranial decreased and nerol, geraniol, citronellal, citronellol, 2,6-dimethyl-2,6octadiene, and geranyl acetate appeared (Fig. 3d).

On the other hand, no difference was observed between the presence and absence of yeast for linalool, which is commonly contained in the perilla leaf reaction solutions of several essential oil types, and for the following components contained in perilla leaf reaction solutions of each essential oil type: PP type, myristicin; EK type, elsholtziaketone, naginataketone, 3-phenyl butanol; PT type, piperitenone, piperitone, carvone; PL type, perillene; and C type, methyl geranate.

\section{3. GC-MS analysis of the hexane extract fraction of each reaction mixture}

We investigated the reaction of all components not volatile at $60^{\circ} \mathrm{C}$ (and thus not detected by SPME-GC-MS analysis) by GC-MS analysis of the hexane fractions of reaction mixtures comprising yeast added to perilla leaf immersion liquid of each essential oil type and reaction mixtures comprising only perilla leaf immersion liquid of each essential oil type. After incubation for 0 and $48 \mathrm{~h}$, no component not detected by SPME was observed and peak areas were unchanged by the presence or absence of yeast (data not shown). Thus, we were unable to confirm the bioconversion by yeast of components contained in the perilla strain tested in this study that are non-volatile at $60^{\circ} \mathrm{C}$ and that elute in hexane (detectable in this experiment).

\section{Discussion}

The bioconversion of perilla essential oil components by yeast observed in this study may be due to the reduction of $\mathrm{C}=\mathrm{C}$ bonds and of aldehydes, as well as to esterification and dehydration reactions (Figs. 4-6). It has been known since antiquity that $S$. cerevisiae produces ethanol via fermentation and this yeast has long been used in the brewing of wine, beer and sake. The yeast strain S. cerevisiae NBRC 2260 used in this study is a wine yeast (OC-2).

Monoterpene compounds are plant secondary metabolites whose basic structure is generated catalytically by enzymes using geranyl diphosphate GPP as a substrate. Various enzymes such as cytochrome P450 monooxygenase generate monoterpenes with different structures. Perillaketone is presumed to be formed from isoegomaketone in the perillaketone biosynthetic pathway in PK type perilla by an unidentified enzyme. The conversion from isoegomaketone to perillaketone by yeast likely involves old yellow enzyme (OYE). OYE-like family of enzymes are present in various 
microorganisms and plants, including Saccharomyces pastorianus (OYE 1) and S. cerevisiae (OYE 2, OYE 3, Lot 6p), and reduce the $\mathrm{C}=\mathrm{C}$ double bond adjacent to an electron withdrawing group such as an aldehyde group in the presence of NADPH (23). OYE1, 2, and 3 reduce citral (geranial and neral) to form citronellal (24), and OYE 2 is mainly involved in the reduction of geraniol to citronellol by $S$. cerevisiae (25).

Figure 7 shows two potential routes for the generation of citronellol from citral. In route I, first the aldehyde group of citral is reduced to form geraniol and nerol, then the $\mathrm{C}=\mathrm{C}$ double bond is further reduced to form citronellol. In route II, first the $\mathrm{C}=\mathrm{C}$ double bond of citral is reduced to form citronellal and then the aldehyde group of citronellal is reduced to form citronellol. The peaks due to geraniol and nerol increased at $24 \mathrm{~h}$ after adding yeast, then remained unchanged at $48 \mathrm{~h}$, whereas citronellal was detected immediately after adding yeast and decreased after 24 to $48 \mathrm{~h}$ (Fig. 3d, YC 0, 24, 48). This suggests that citronellol is formed via route II (from citral via citronellal). We also investigated the bioconversion from perillaldehyde to trans-shisool and observed that the peak due to perillyl alcohol increased at $24 \mathrm{~h}$ after the addition of yeast and then remained unchanged at $48 \mathrm{~h}$, whereas 1,2-dihydroperillaldehyde was detected only immediately after the addition of yeast (Fig. 3b, YPA 0, 24, 48). These results suggest that the $\mathrm{C}=\mathrm{C}$ double bond of perillaldehyde is reduced to form $1,2-$ dihydroperillaldehyde whose aldehyde group is further reduced to form trans-shisool, likely by alcohol dehydrogenases expressed in S. cerevisiae (26).

Alcohol acetyltransferase (ATF) 1 and 2 are likely involved in the esterification of perillyl alcohol to perillyl acetate and geraniol to geranyl acetate. S. cerevisiae bioconversion of geraniol involves ATF1 to form terpenyl acetate. Esterification of citronellol by $S$. cerevisiae overexpressing ATF1 was slower than that of geraniol or nerol (25). However, in the present study, neryl acetate and citronellyl acetate were not detected in the reaction mixture (Fig. 3d), perhaps due to the small amount of nerol and the low esterification rate of citronellol. Similarly, trans-shisool may have been esterified by $S$. cerevisiae but was not detected in this study (Fig. 3b).

Isolimonene is likely generated by the dehydration of trans-shisool and 2,6dimethyl-2,6-octadiene produced from citronellol. The reactions may include two steps: isomerization and dehydration. However, no component likely to be an intermediate was detected (Fig. 3b, d), so these reactions might occur very rapidly and no intermediates could be detected. Linalool dehydratase (LinD) in Castellaniella defragrans catalyzes the dehydration of linalool to $\beta$-myrcene (27). Dehydratase in $S$. cerevisiae have not been reported but $S$. cerevisiae might catalyze the dehydration of trans-shisool and citronellol.

The $S$. cerevisiae strain used in this study did not bioconvert the monoterpene carvone, although OYE-like enzymes OYE 1 (28), TOYE (29), and PETN (30) have been shown to reduce carvone to dihydrocarvone. Using the same compound as a substrate can result in different products and composition ratios depending on the species and strain of microorganism $(11,12,15,31)$. In particular, in S. cerevisiae, the 
amount of linalool produced from geraniol is reported to vary from strain to strain (15), but we found no difference in the amount of linalool with or without the addition of yeast in this study. It has also been reported that baker's yeast produces trans-shisool and perillyl alcohol from perillaldehyde (16), and that the non-conventional yeast Kazachstania naganishii produces dihydroperillaldehyde, dihydroperillic alcohol, and perillyl alcohol from perylaldehyde (17). However, there have been no reports of production of isolimonene or perillyl acetate, which was revealed in this study. Several microbial species other than $S$. cerevisiae that reduce perillaldehyde have also been reported (14, 17, 21), and Yarrowia lipolytica (6) and Pseudomonas putida (18) oxidize limonene to form perillyl alcohol, perillaldehyde, and perillic acid. From these results, the compound recognized as a substrate and the type of catalysis reaction (redox, dehydration, isomerization, and cyclization) differ depending on the microorganism species. Compounds having similar structures are subjected to similar conversion reactions by a microorganism but whether this conversion occurs cannot be predicted. In this study, we revealed that monoterpene compounds contained in perilla essential oil are bioconverted by $S$. cerevisiae. The $\alpha, \beta$-unsaturated carbonyl compounds perillaldehyde, isoegomaketone, neral, and geranial are recognized as substrates by yeast and have less steric hindrance around the $\mathrm{C}=\mathrm{C}$ bond conjugated to their aldehyde or ketone group compared with elsholtziaketone, naginataketone, piperitenone, piperitone, and carvone, which are highly sterically hindered and are not bioconverted by yeast. In esterification, the difference in the reactivity of yeast toward geraniol and citronellol is likely due to steric differences depending on the presence or absence of the $\mathrm{C}=\mathrm{C}$ bond next to the alcohol group, with geraniol more likely to bind to the active site of the enzyme ATF1.

Bioconversion is not only substrate-specific but also often highly stereo- and regiospecific. Therefore, it can be applied in the synthesis of complex structures and in asymmetric synthesis. For example, the OYE-like family enzyme TOYE (29) and PETN (30) can be used to reduce the $\mathrm{C}=\mathrm{C}$ bond in the cyclohexene ring of carvone and the one in the enal group of citral to form dihydrocarvone and citronellal with high optical purity. In another example, the actinomycete Pseudonocardia autotrophica is known to convert vitamin $\mathrm{D}_{3}$ stereo- and regiospecifically into its physiologically active form, calcitriol (1 $\alpha, 25$-dihydrovitamin $\mathrm{D}_{3}$ ) (32). By using this reaction system, the productivity of calcitriol synthesis was improved in comparison with conventional chemical synthesis. Similarly, bioconversion also has utility in the synthesis of pharmaceuticals.

The results of this study make a valuable contribution toward elucidating the changes in volatile compounds during the brewing of perilla leaves. Monoterpene compounds are used in flavors and perfumes because they generally have a pleasant smell and volatilize at room temperature. Some monoterpene compounds have pharmacological actions such as antitumor and sedative activities and are thus 
pharmaceutically useful. Research on the bioconversion of monoterpene compounds is applicable to pharmaceuticals, foods, and cosmetics.

\section{Acknowledgments}

This project was partially performed as a cooperative project with Oenon Holdings, Inc.

\section{Disclosure statement}

The authors declare the following potential financial conflicts of interest. Joint research fund: Oenon Holdings, Inc.

\section{References}

1. Koezuka Y, Honda G and Tabata M,

An Intestinal Propulsion Promoting Substance from Perilla frutescens and Its Mechanism of Action. Planta Medica, 51, 6, 480-482 (1985)

2. Sato K, Krist S and Buchbauer G, Antimicrobial effect of trans-cinnamaldehyde, (-)perillaldehyde, (-)-

citronellal, citral, eugenol and carvacrol on airborne microbes using an airwasher. Biological and Pharmaceutical Bulletin, 29, 11, 2292-2294 (2006)

3. Takagi S, Goto H, Shimada Y, Nakagomi K, Sadakane Y, Hatanaka Y and Terasawa $\mathrm{K}$, Vasodilative effect of perillaldehyde on isolated rat aorta. Phytomedicine, 12, 5, 333-337 (2005)

4. Ito N, Nagai T, Oikawa T, Yamada H and Hanawa T, Antidepressant-like Effect of lperillaldehyde in Stress-induced Depressionlike Model Mice through Regulation of the OlfactoryNervous System. Evidence-Based Complementary and Alternative Medicine, 2011, 512697 (2011)

5. Trombetta D, Castelli F, Sarpietro MG, Venuti V, Cristani M, Daniele C, Saija A, Mazzanti G and Bisignano G, Mechanisms of antibacterial action of three monoterpenes. Antimicrobial Agents and Chemotherapy, 49, 6, 2474-2478 (2005)

6. Guzmán-Gutiérrez SL, Gómez-Cansino R, García-Zebadúa JC, Jiménez-Pérez NC and Reyes-Chilpa R, Antidepressant activity of Litsea glaucescens essential oil: identification of $\beta$-pinene and linalool as active principles. Journal of Ethnopharmacology 143, 2, 673-679 (2012)

7. Ito $\mathrm{K}$ and Ito $\mathrm{M}$, The sedative effect of inhaled terpinolene in mice and its structureactivity relationships. Journal of Natural Medicines, 67, 4, 833-837 (2013) 
8. Mills JJ, Chari RS, Boyer IJ, Gould MN and Jirtle RL, Induction of apoptosis in liver tumors by the monoterpene perillyl alcohol. Cancer Research, 55, 5, 979-983 (1995)

9. Erman MB and Kane BJ, Chemistry around pinene and pinane: a facile synthesis of cyclobutanes and oxatricyclo-derivative of pinane from cis- and trans-pinanols. Chemistry \& Biodiversity, 5, 6, 910-919 (2008)

10. Rozenbaum HF, Patitucci ML, Antunes OAC and Pereira Jr N, Production of aromas and fragrances through microbial oxidation of monoterpenes. Brazilian Journalof ChemicalEngineering, 23, 3, 273-279 (2006)

11. Vespermann KA, Paulino BN, Barcelos MC, Pessôa MG, Pastore GM and Molina $\mathrm{G}$, Biotransformation of $\alpha$ - and $\beta$-pinene into flavor compounds. Applied Microbiology and Biotechnology, 101, 5, 1805-1817 (2017)

12. Chalchat JC, Garry RP, Michet A and Veschambre H, Bioconversion of Terpinolene and Its 4, 8-Epoxide. Journal of Essential Oil Research, 4, 3, 235-238 (1992)

13. Cardillo R, Nasini G, Vajna $O$ and Pava D, Isolation of illudin M, illudinine and shisool from the mushroom Clitocybe phosphorea; biotransformation of perillyl alcohol and aldehyde. Phytochemistry, 31, 6, 2013-2014 (1992)

14. Noma Y, Akehi E, Miki N and Asakawa Y, Biotransformation of terpene aldehydes, aromatic aldehydes and related compounds by Dunaliella Tertiolecta. Phytochemistry, 31, 2, 515-517 (1992)

15. Ferrara MA, Almeida DS, Siani AC, Lucchetti L, Lacerda PS, Freitas A, Tappin $\mathrm{MR}$, and Bon EP, Bioconversion of R-(+)-limonene to perillic acid by the yeast Yarrowia lipolytica. Brazilian Journal of Microbiology, 44, 4. 10751080 (2013)

16. Gamero A, Manzanares P, Querol A and Belloch C, Monoterpene alcohols release and bioconversion by Saccharomyces species and hybrids. International Journal of Food Microbiology, 145, 92-97 (2011)

17. Goretti M, Ponzoni C, Caselli E, Marchegiani E, Cramarossa MR, Turchetti B, Forti $\mathrm{L}$ and Buzzini P, Bioreduction of $\alpha, \beta$-unsaturated ketones and aldehydes by nonconventional yeast (NCY) whole-cells. Bioresource Technology, 102, 39933998 (2011)

18. Speelmans G,Bijlsma A and Eggink G, Limonene bioconversion to high concentrations of a single and stable product, perillic acid, by a solventresistant Pseudomonas putida strain. Applied Microbiology and Biotechnology, 50, 538-544 (1998)

19. Holt S, Miks MH, de Carvalho BT, Foulquié-Moreno MR and Thevelein JM, The molecular biology of fruity and floral aromas in beer and other alcoholic beverages. FEMS Microbiology Reviews, 1, 43, 3, 193-222 (2018) 
20. Fujiwara Y and Ito M, Molecular cloning and characterization of a Perilla frutescens cytochrome P450 enzyme that catalyzes the later steps of perillaldehyde biosynthesis. Phytochemistry, 134, 26-37 (2007)

21. Fronza G, Fuganti C, Pinciroli M and Serra S, Stereochemical aspects of the bioreduction of the conjugated double bond of perillaldehyde. Tetrahedron Asymmetry, 15, 19, 3073-3077(2004)

22. Ito M, Toyoda M, Yuba A and Honda G, Chemical Compositon of the Essential Oil of Perilla Frutescens. Natural Medicines, 53, 1, 32-36 (1999)

23. Toogood HS, Gardiner JM and Scrutton NS, Biocatalytic Reductions and Chemical Versatility of the Old Yellow Enzyme Family of Flavoprotein Oxidoreductases. ChemCatChem, 2, 8, 892-914 (2010)

24. Müller A, Hauer B and Rosche B, Asymmetric alkene reduction by yeast old yellow enzymes and by a novel Zymomonas mobilis reductase. Biotechnology and Bioengineering, 98, 1, 22-29 (2007)

25. Steyer D, Erny C, Claudel P, Riveill G, Karst F and Legras JL, Genetic analysis of geraniol metabolism during fermentation. Food Microbiology, 33, 2, 228-234 (2013)

26. de Smidt O, du Preez JC and Albertyn J, The alcohol dehydrogenases of Saccharomyces cerevisiae: a comprehensive review. FEMS Yeast Research, 8, 7, 967-978 (2008)

27. Ling B, Wang X, Su H, Liu R and Liu Y. Protonation state and fine structure of the active site determine the reactivity of dehydratase: hydration and isomerization of $\beta$-myrcene catalyzed by linalool dehydratase/isomerase from Castellaniella defragrans. Physical Chemistry Chemical Physics, 20, 25, 7342-17352 (2018)

28. Padhi SK, Bougioukou DJ and Stewart JD, Site-saturation mutagenesis of tryptophan 116 of Saccharomyces pastorianus old yellow enzyme uncovers stereocomplementary variants. Journal of the American Chemical Society, 131, 9, 3271-3280 (2009)

29. Adalbjörnsson BV, Toogood HS, Fryszkowska A, Pudney CR, Jowitt TA, Leys D and Scrutton NS, Biocatalysis with thermostable enzymes: structure and properties of a thermophilic 'ene'-reductase related to old yellow enzyme. ChemBioChem, 11, 2, 197-207 (2010)

30. Fryszkowska A, Toogood H, Sakuma M, Gardiner JM, Stephens GM and Scrutton NS,

Asymmetric Reduction of Activated Alkenes by Pentaerythritol Tetranitrate Red uctase: Specificityand Control of Stereochemical Outcome by Reaction Optimis ation. Advanced Synthesis \& Catalysis, 351, 17, 2976-2990 (2009)

31. Ponzoni C, Gasparetti C, Goretti M, Turchetti B, Pagnoni UM, Cramarossa MR, Forti L and Buzzini P, Biotransformation of acyclic monoterpenoids by Debaryomyces sp., Kluyverom 
yces sp., and Pichia sp. strains of environmental origin. Chemistry \& Biodiversity, 5. 471-483 (2008)

32. Fujii Y, Kabumoto H, Nishimura K, Fujii T, Yanai S, Takeda K, Tamura $\mathrm{N}$, Arisawa A, Tamura T Purification, characterization, and directed evolution study of a vitamin D3 hydroxylase from Pseudonocardia autotrophica. Biochemical and Biophysical Research Communications, 385, 2, 170-175 (2009) 


\section{Figures}

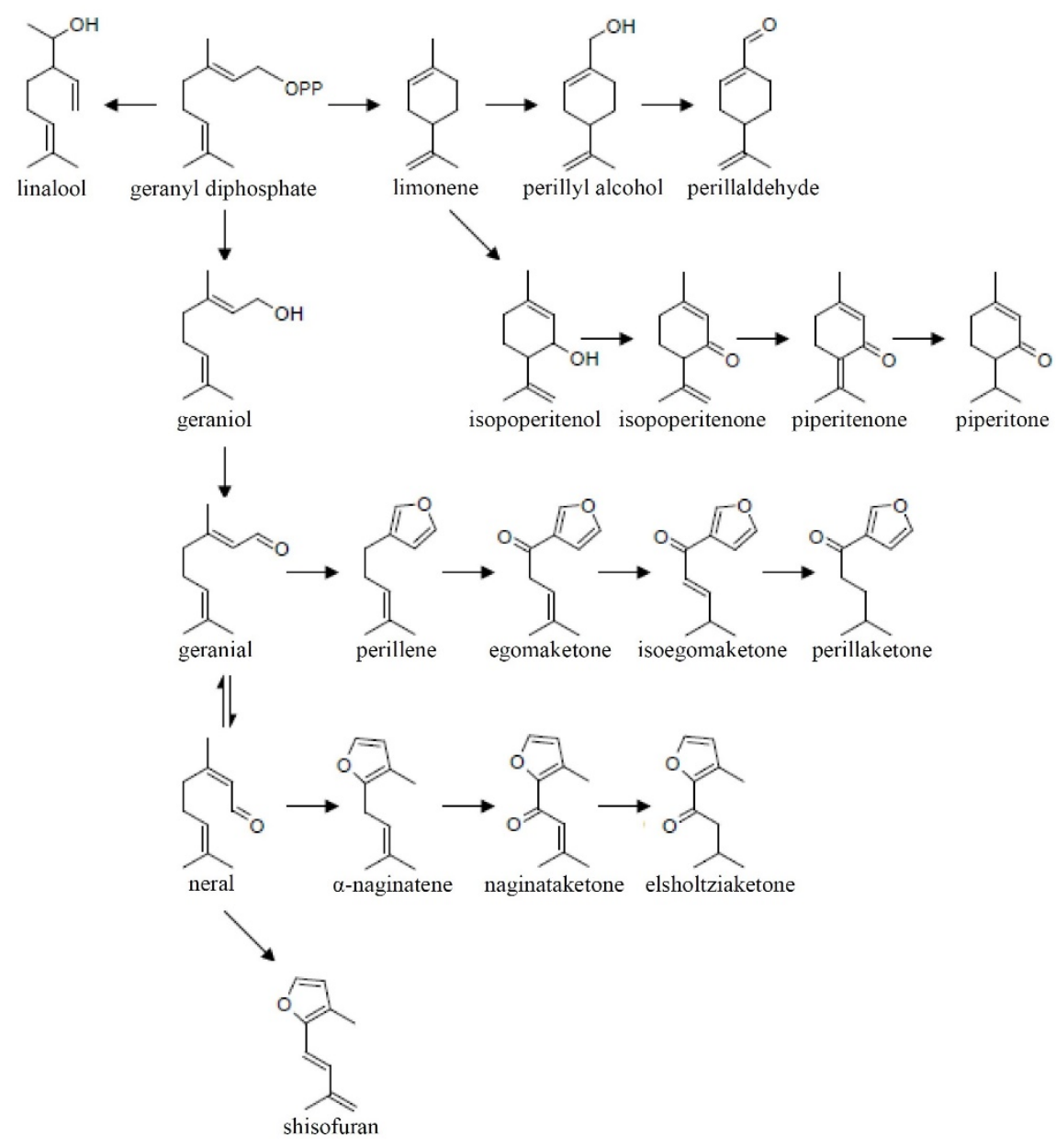

Figure 1 Putative biosynthetic pathway for essential oil components in monoterpene type perilla.

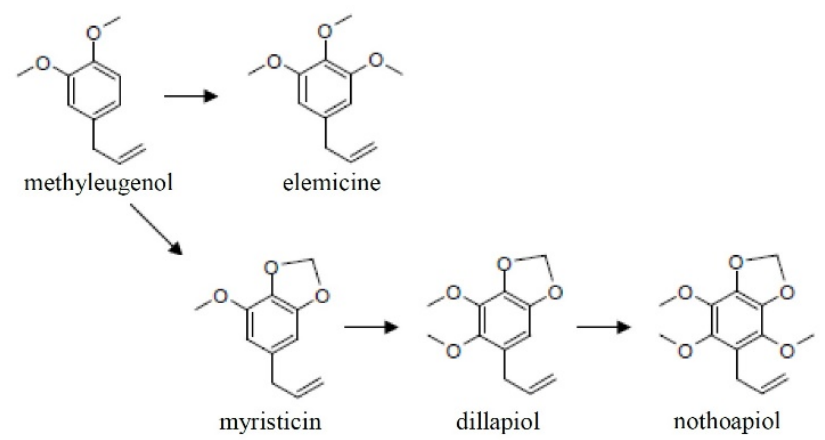

Figure 2 Putative biosynthetic pathway for essential oil components in phenyl propene type perilla. 

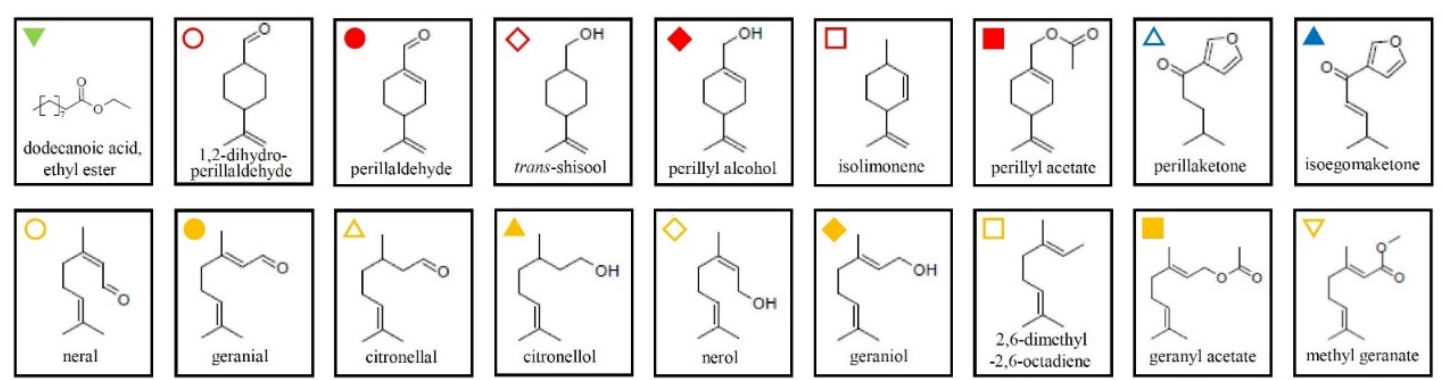

a $\quad \mathrm{Y} 0$
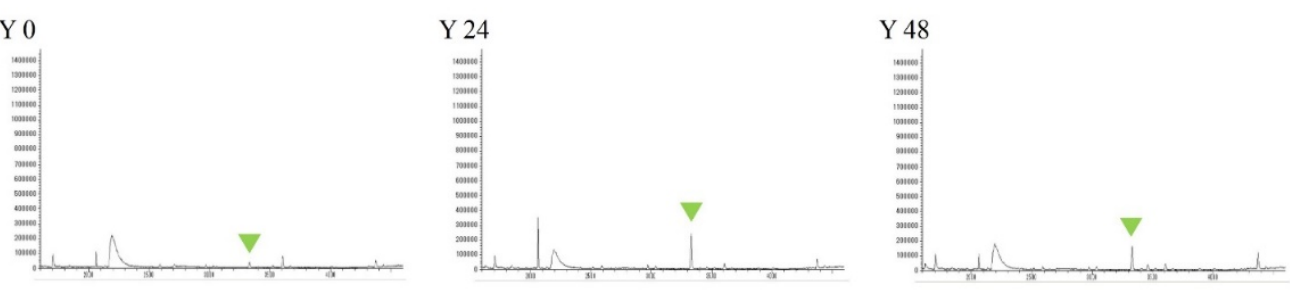

b YPA 0

PA 0
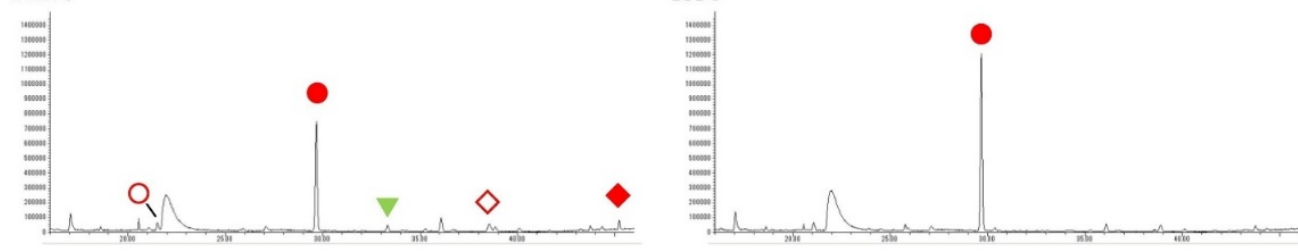

YPA 24

PA 24

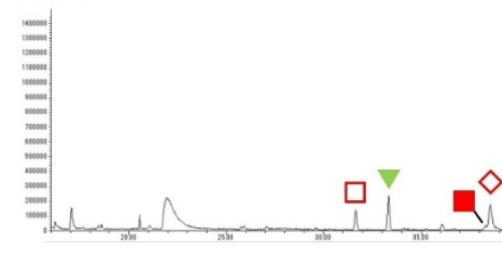

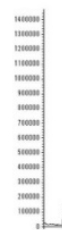
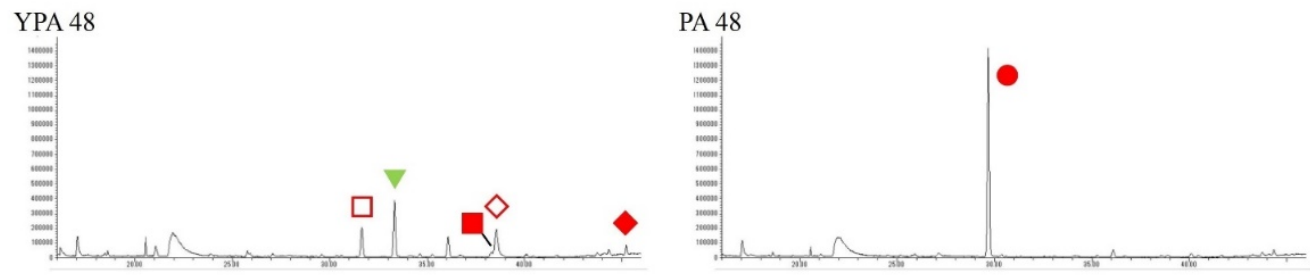
c

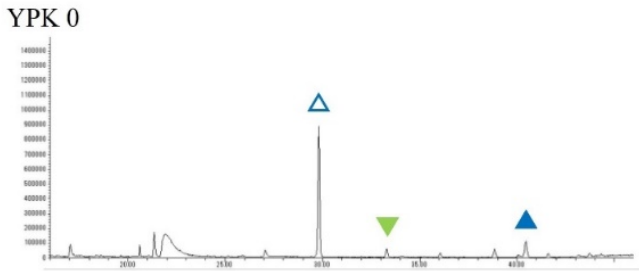

YPK 24
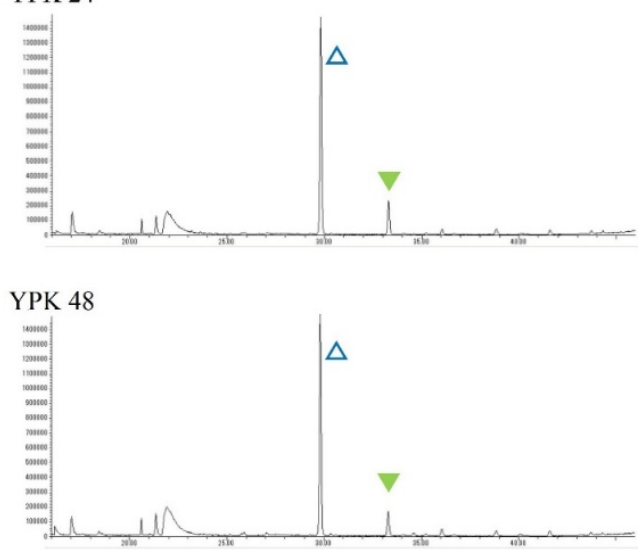

d $\mathrm{YC} 0$

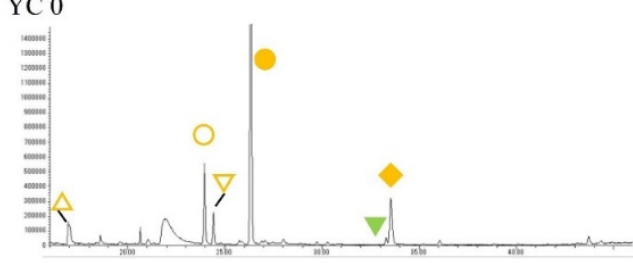

YC 24
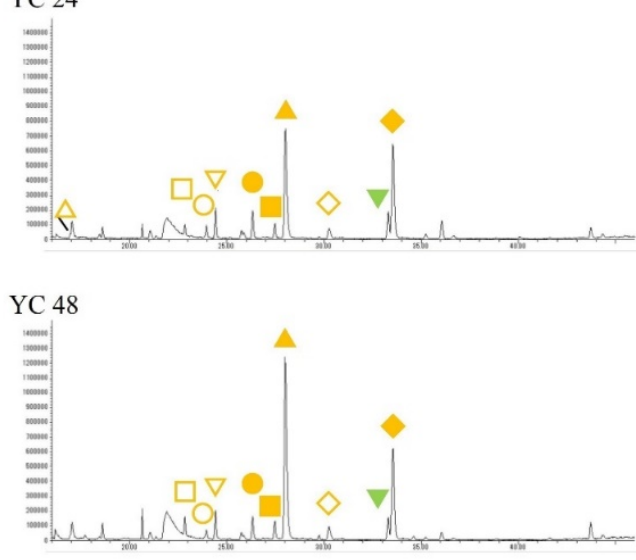

PK 0

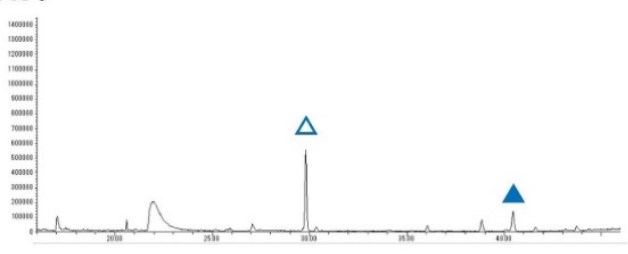

PK 24
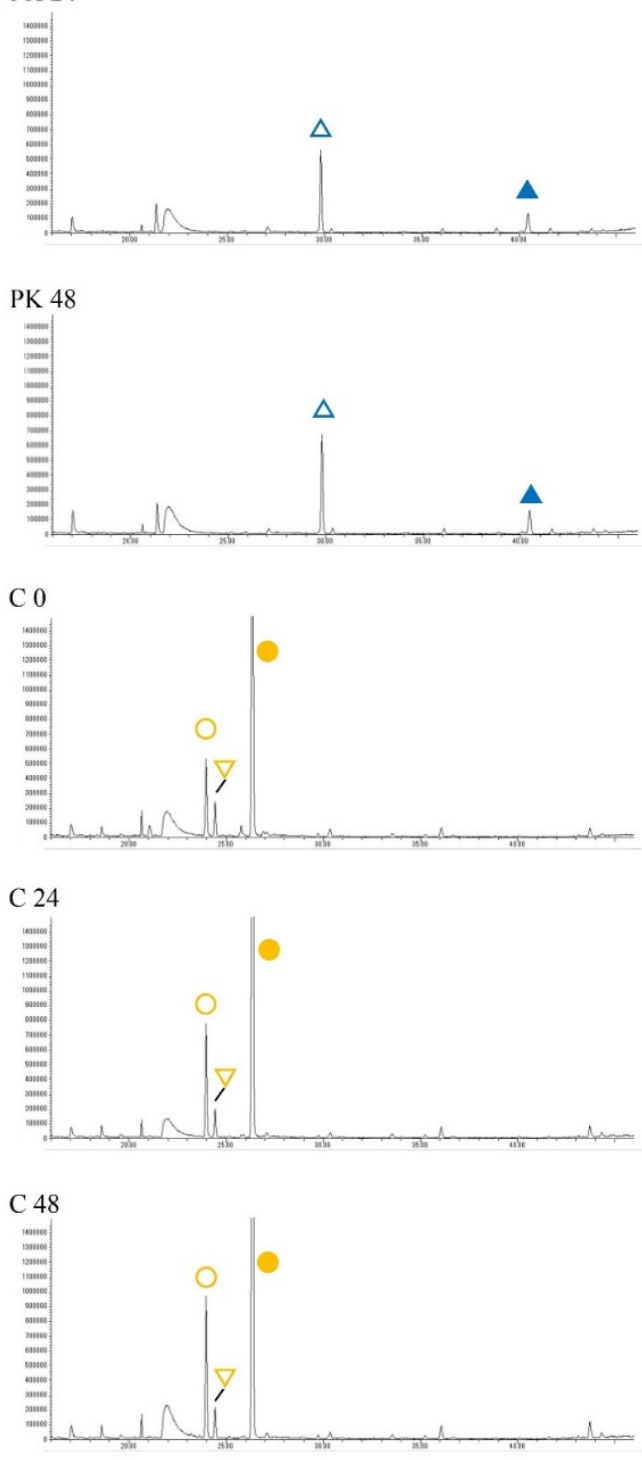

Fig. 3 SPME-GC-MS profiles of reaction mixtures. a reaction mixtures after incubation for 0 , 24, and $48 \mathrm{~h}$ comprising yeast in $10 \%$ aqueous ethanol ( $\mathrm{Y} 0,24,48)$. b reaction mixtures after incubation for 0,24 , and 48 h comprising PA type (No. 5343) leaf immersion liquid with yeast added (YPA 0, 24, 48) or not added (PA 0, 24, 48). c reaction mixtures after incubation for 0,24 , and $48 \mathrm{~h}$ comprising PK type (No. 63) leaf immersion liquid with yeast added (YPK 0, 24, 48) or not added (PK 0, 24, 48). d reaction mixtures after incubation for 0,24 , and $48 \mathrm{~h}$ comprising $\mathrm{C}$ type (No. 5809) leaf immersion liquid with yeast added(YC $0,24,48)$ or not added (C $0,24,48)$. The profiles are total ion chromatograms. Green closed inverted triangles: dodecanoic acid 
ethyl ester; red open circles: 1,2-dihydroperillaldehyde; red closed circles:

perillaldehyde; red open diamonds: perillyl alcohol; red closed diamonds: trans-shisool; red open squares are isolimonene; red closed squares: perillyl acetate; blue open triangles: perillaketone; blue closed triangles: isoegomaketone; yellow open circles: neral; yellow closed circles: geranial; yellow open diamonds: nerol; yellow closed diamonds: geraniol; yellow open triangles: citronellal; yellow closed triangles: citronellol: yellow open squares: 2,6-dimethyl-2,6-octadiene; yellow closed squares: geranyl acetate; yellow open inverted triangles: methyl geranate.

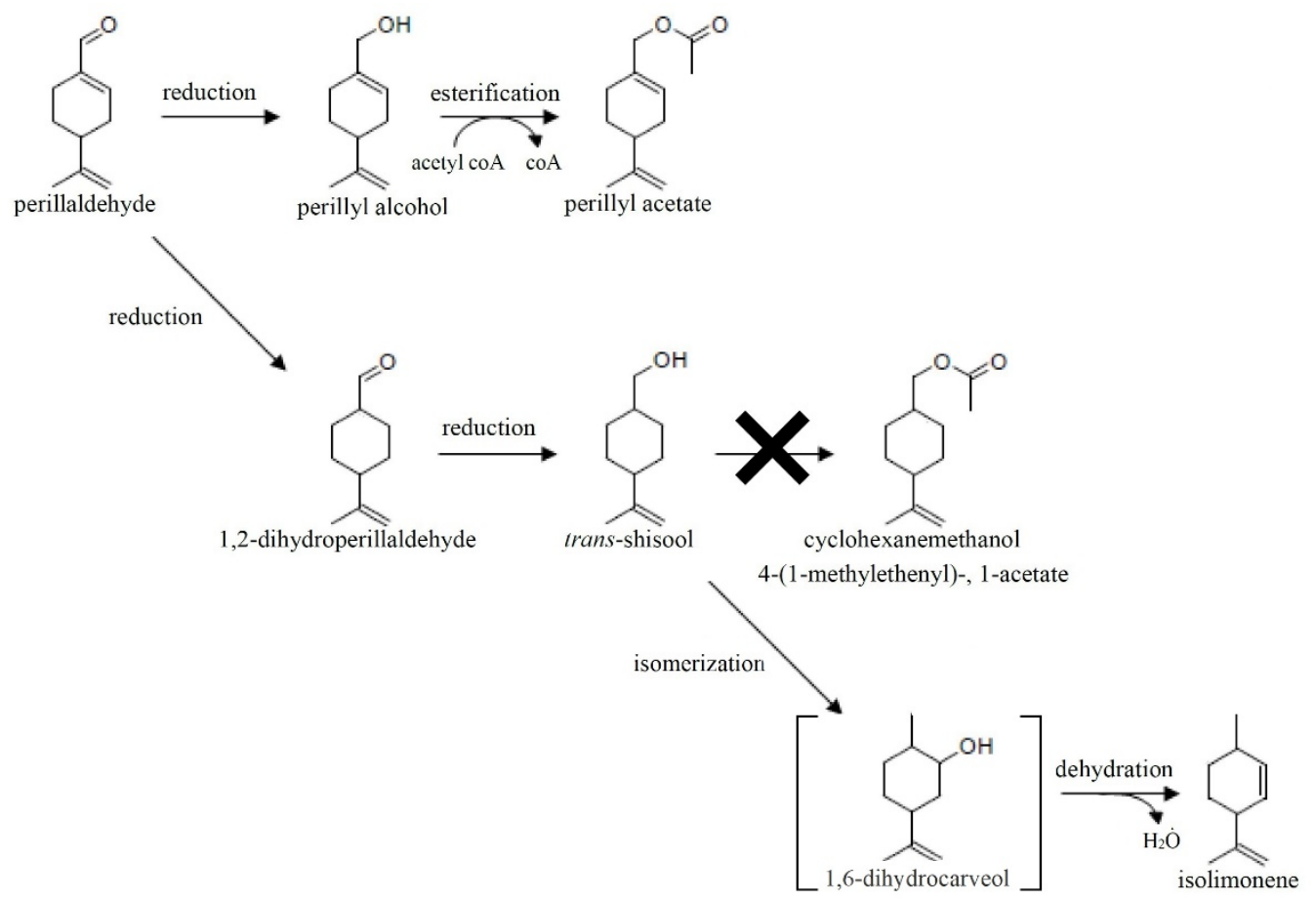

Figure 4 Putative bioconversion pathway of perillaldehyde.

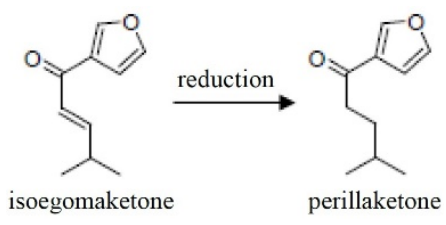

Figure 5 Putative bioconversion pathway of isoegomaketone. 
$\overbrace{\text { geranial }} \stackrel{N_{\text {reduction }}^{\longrightarrow}}{\longrightarrow}$

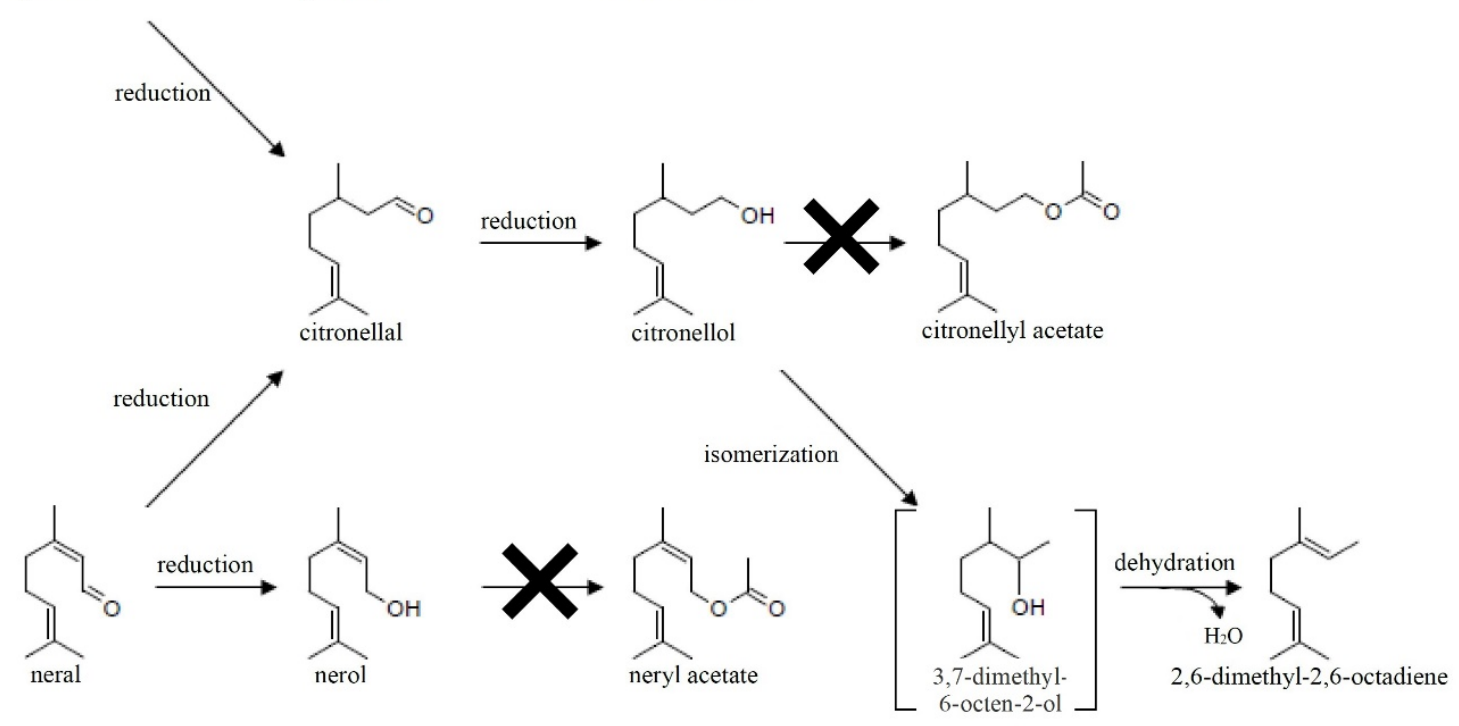

Figure 6 Putative bioconversion pathway of geranial and neral.

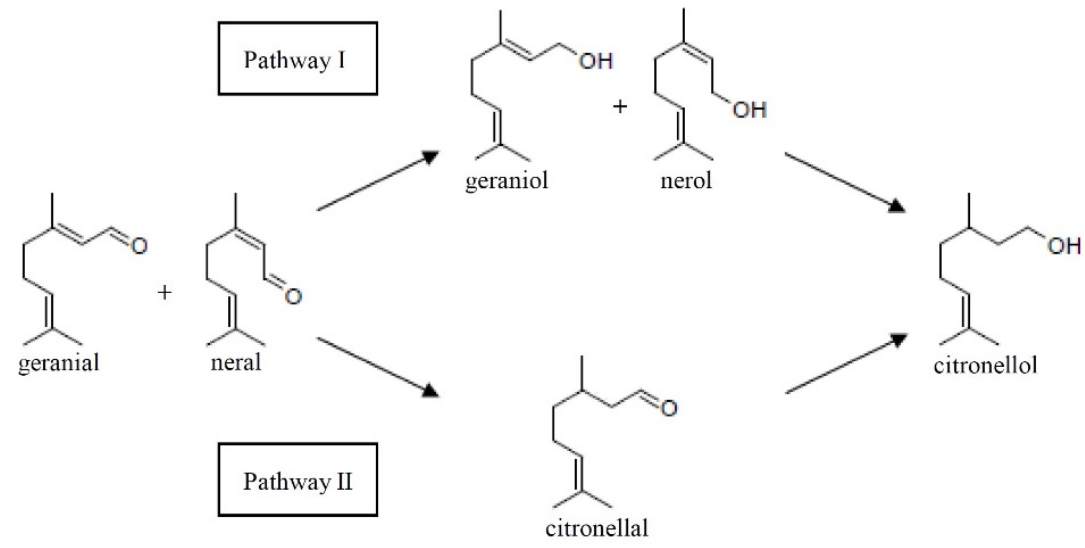

Figure 7 Possible bioconversion pathways from citral to citronellol. 


\section{Supplemental data}

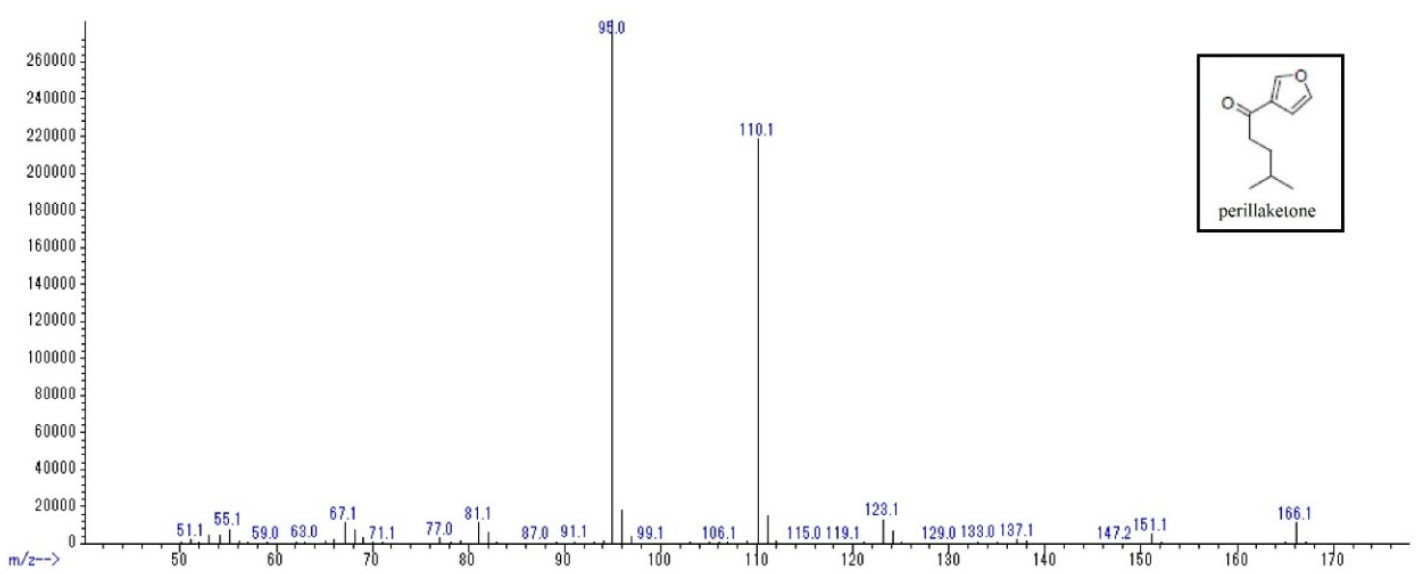

Figure S1 Mass spectrum of the peak attributed to perillaketone (RT 29.81)

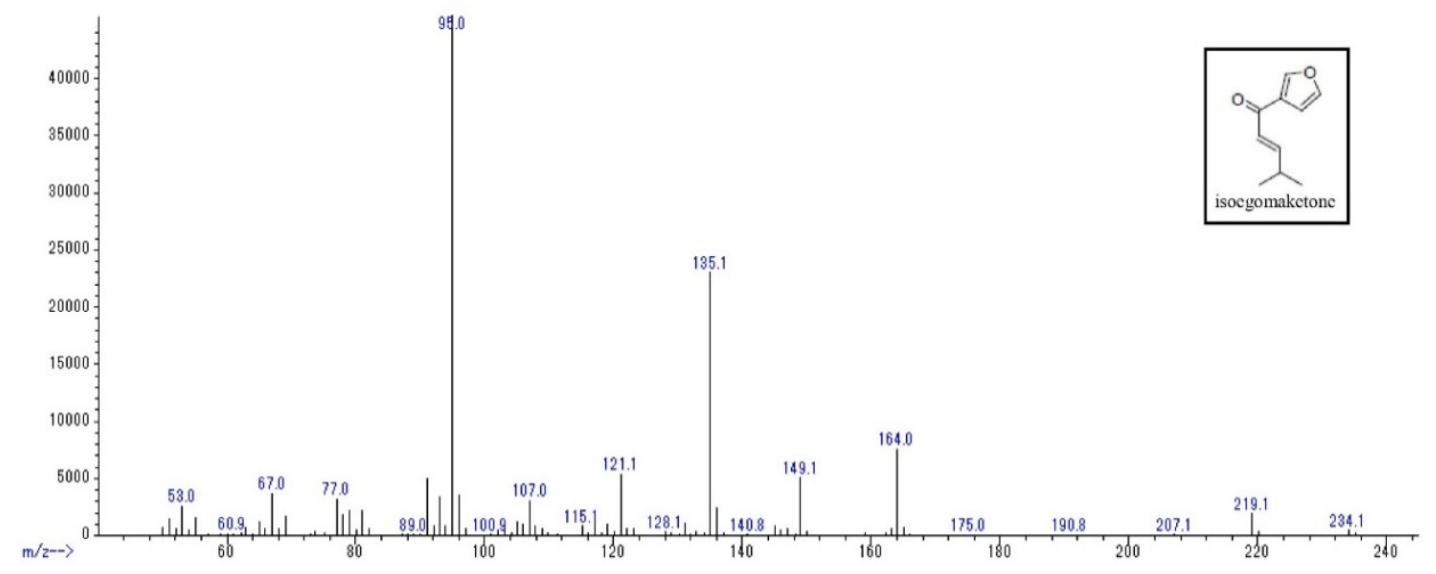

Figure S2 Mass spectrum of the peak attributed to isoegomaaketone (RT 40.46)

Table S1 Viable cell count at 24 and $48 \mathrm{~h}$ after yeast fermentation of perilla leaf immersion liquid of each essential oil type.

\begin{tabular}{llcc}
\hline $\begin{array}{l}\text { Perilla strain } \\
\text { Essential oil type }\end{array}$ & Strain No. & \multicolumn{2}{c}{ Viable cell count $*\left(\times 10^{5}\right.$ cells $\left./ \mathrm{mL}\right)$} \\
After $24 \mathrm{~h}$ & $\mathrm{~A}$ \\
\hline PA type & 32 & $15.7 \pm 2.6$ & $25.0 \pm 0.0$ \\
& 5343 & $20.9 \pm 2.0$ & $29.8 \pm 1.5$ \\
PP type & 1 & $21.5 \pm 3.4$ & $22.1 \pm 3.3$ \\
PK type & 63 & $26.1 \pm 2.9$ & $27.8 \pm 1.8$ \\
EK type & 79 & $24.4 \pm 1.9$ & $25.1 \pm 2.0$ \\
PL type & 1869 & $23.0 \pm 4.2$ & $25.9 \pm 0.6$ \\
PT type & 5598 & $22.6 \pm 5.3$ & $23.5 \pm 2.3$ \\
C type & 5809 & $23.5 \pm 1.0$ & $22.4 \pm 0.9$ \\
Yeast only (control) & & $8.7 \pm 0.9$ & $7.4 \pm 1.6$ \\
* Viable cell count $\left(\times 10^{5}\right.$ cells $\left./ \mathrm{mL}\right)$ is the average value obtained from two independent \\
experiments
\end{tabular}

